\section{Diabetes Mellitus and Sexual Dysfunction; A Systematic Review of the Literature with Current Treatment Approaches}

\author{
Caner Ediz and Ramazan Altintas* \\ Department of Urology, Inonu University, Medicine Faculty, Malatya, \\ Turkey
}

\begin{abstract}
Diabetes mellitus is a chronic disease in nearly all countries. Both men and women with diabetes can develop sexual problems because of damage to nerves and small blood vessels. Diabetes mellitus is one of the predominant risk factors of Erectile Dysfunction $(E D)$ in men.
\end{abstract}

Sexual dysfunction is a common, underappreciated complication of diabetes. Male sexual dysfunction among diabetic patients can include disorders of libido, ejaculatory problems, and erectile dysfunction. All three forms of male dysfunction can cause significant bother for diabetic patients and can affect their quality of life. While all three forms of male sexual dysfunction can be found among diabetic men, this review will focus on the most common form, ED, because the literature is most mature in this area.

Erectile dysfunction due to diabetes mellitus remains difficult to treat medically despite advances in pharmacotherapeutic approaches in the field. Diabetes-induced ED is often resistant to PDE5 inhibitor treatment, thus there is a need to discover targets that may lead to novel approaches for a successful treatment. We aim to discuss diabetes mellitus patients who have sexual dysfunction to treatment with current approaches in the literature.

Keywords: Diabetes mellitus; Diabetes complications; Erectile dysfunction; Lifestyle changes; Erectile dysfunction treatment

\section{Introduction}

Diabetes mellitus is one of the most common chronic diseases in nearly all countries; it is increasing rapidly in every part of the world, to the extent that it has now assumed epidemic proportions. In 2012,

*Corresponding author: Ramazan Altintas, Urology Department, Inonu University, 44280, Malatya, Iruma-gun, Turkey, Tel: 0-422-341-0660-5804; Fax: 0-422-34- 0728; E-mail: drkaneru@hotmail.com

Citation: Ediz C, Altintas R (2014) Diabetes Mellitus and Sexual Dysfunction A Systematic Review of the Literature with Current Treatment Approaches. J Diabetes Metab Disord 1: 001.

Received: May 31, 2014; Accepted: June 25, 2014; Published: July 09, 2014

Copyright: (c) 2014 Ediz C and Altintas R, This is an open-access article distributed under the terms of the Creative Commons Attribution License, which permits unrestricted use, distribution, and reproduction in any medium, provided the original author and source are credited. more than 382 million people had diabetes and this is expected to rise to 595 million by 2035 [1] rendering previous estimates very conservative and in the US, diabetes is the fifth leading cause of death for men [2]. It is also a leading cause of death in most developed countries [1].

Several behavioral and environmental factors have contributed to the rise in diabetes incidence in industrialized countries, including overweight (Body Mass İndex [BMI], $\geq 25 \mathrm{~kg} / \mathrm{m} 2$ ), obesity (BMI, $\geq 30$ $\mathrm{kg} / \mathrm{m} 2$ ), physical inactivity, and increased caloric consumption; these have all been shown to be major risk factors for the development of type 2 diabetes, regardless of age and sex [3].

Diabetes mellitus is associated with both macrovascular (including cardiovascular disease) and microvascular (including retinopathy, nephropathy, and neuropathy) complications $[4,5]$. People with diabetes are at a greater risk of developing Cardiovascular Diseases (CVD), such as heart attack and stroke.

Diabetes has been associated with sexual dysfunction in men [6,7]. Diabetes is an established risk factor for sexual dysfunction in men; a threefold increased risk of Erectile Dysfunction (ED) was documented in diabetic compared with nondiabetic men $[6,8]$. It is still not clear whether hyperglycemia, which is a main determinant of vascular diabetic complications, may participate in the pathogenetic mechanisms of sexual dysfunction in diabetes. Otherwise, diabetic people may present with several clinical conditions, including hypertension, cigarette smoking, obesity, metabolic syndrome or dyslipidemia, which are themselves risk factors for sexual dysfunction in both sexes $[9,10]$.

\section{Erectile Dysfunction}

Erectile Dysfunction (ED) is defined as the persistent inability to achieve or maintain penile erection for successful sexual intercourse [11] causing decreased quality of life in men [12,13]. Epidemiological data have shown a high prevalence and incidence of ED worldwide. $\mathrm{ED}$ is a common sexual disorder that increases with age. According to a recent analysis of published works on the prevalence of sexual dysfunction by the International Consultation Committee for Sexual Medicine on Definitions/Epidemiology/Risk Factors for Sexual Dysfunction [14] the prevalence of ED was $1 \%-10 \%$ in men younger than 40 years, $2 \%-9 \%$ among men between 40 and 49 years, and it increased to $20 \%-40 \%$ among men between $60-69$ years, reaching the highest rate in men older than 70 years (50\%-100\%). In the Massachusetts Male Aging Study [6] diabetic men showed a threefold probability of having ED than men without diabetes; moreover, the age-adjusted risk of ED was doubled in diabetic men compared with those without diabetes [15]. In addition, it has been estimated that the worldwide prevalence of ED will rise to 322 million cases by the year 2025 [16,17]. Several cross-sectional and longitudinal studies showed an association between ED and most of the cardiovascular risk factors, such as diabetes $[6,12,18]$, smoking [19], hypertension [20], hyperlipidemia [21], depression [22], metabolic syndrome [23], lower urinary tract symptom [24], and poor health state [12]. Moreover, ED can be easily detected by having male patients complete standardized questionnaires investigating their 
sexual function. One of the most practical questionnaires that is administered is the International Index of Erectile Function (IIEF) [25].

\section{ED and Diabetes: Risk Factors and Association}

Diabetes mellitus is one of the predominant risk factors of erectile dysfunction and also one of the most difficult to treat. Approximately $50 \%$ of diabetic men will suffer from ED within 10 years of the diagnosis. Epidemiological studies suggest that both type 1 and type 2 diabetes are associated with an increased risk of $\mathrm{ED}$, which is reported to occur in $\geq 50 \%$ of men with diabetes worldwide $[20,26]$. The occurrence of ED is 10-15 years earlier in men with diabetes [6], moreover, ED is more severe [27] and less responsive to oral drugs in diabetes [28,29], leading to reduced quality of life $[13,2]$.

Advanced age and longer duration of diabetes have been associated with an increased risk of ED in diabetic patients $[8,14,30]$. Whether hyperglycemia is a risk factor for the development of ED in diabetic men is still not clear.

Diabetes is commonly associated with hypertension, hyperlipidemia, overweight and obesity, metabolic syndrome, smoking, sedentary lifestyles, and autonomic neuropathy, which are recognized as risk factors for ED [18].

The use of several medications frequently assumed by diabetic patients, such use of $\beta$-blockers, thiazide diuretics, spironolactone, antidepressants, and certain fibrates, have all been associated with an additive deleterious effect on diabetic ED [31,32].

\section{Pathogenesis of ED in Diabetes}

Erection is a neurovascular event that involves spinal and supra spinal pathways. The final common pathway involves the release of Nitric Oxide (NO) from both endothelial cells and neurons. The causes of erectile dysfunction in men with diabetes are complex and involve impairments in nerve, blood vessel, and muscle function. The pathogenesis of ED in diabetes is multifactorial, as it depends on both psychological and organic factors (which play major roles in ED), as well as psychological and relationship issues, which often coexist. The proposed mechanisms of ED in diabetic patients are represented by vasculopathy, neuropathy, visceral adiposity, insulin resistance, and hypogonadism.

Diabetic vasculopathy concerns macroangiopathy, microangiopathy, and endothelial dysfunction. Macrovascular disease in diabetes corresponds to the atherosclerotic damage in the blood vessels, which limits blood flow to the penis. As mentioned, several cardiovascular risk factors associated with diabetes contribute to the genesis of penile arterial insufficiency $[19,20,23]$ all of them converge on endothelial dysfunction, which represents the common denominator leading to vascular ED. For this reason regarding sexual activity, erectile dysfunction may be a significant sign in the case of suspected diabetes and the early diagnosis of vasculopathy in patients with diabetes. The chronic insult of hyperglycemia on the endothelium results in endothelial dysfunction, which has been suggested as the link between ED and CVD [33]. Endothelial dysfunction in diabetes is manifested as the decreased bioavailability of Nitric Oxide (NO), resulting in insufficient relaxation of the vascular smooth muscle of the corpora cavernosa. The potential mechanisms involved an imbalance between the vasoconstrictive and vasorelaxant intracellular pathways favoring increased vasoconstriction $[26,34]$.
Microvascular disease determines ischemic damage in the distal circulation and autonomic and peripheral neuropathy. Both somatic and autonomic neuropathies may contribute to diabetes-induced ED due to the impairment of sensory impulses from the penis to the reflexogenic erectile center [35] and reduced or absent parasympathetic activity necessary for relaxation of the smooth muscle of the corpus cavernosum [36].

\section{Diagnostic Evaluation}

The first step in evaluating ED is always a detailed medical and sexological history of patients and partners when available. The pathophysiology of ED may be vasculogenic, neurogenic, anatomical, hormonal, drug-induced and/or psychogenic Taking a comprehensive medical history may reveal one of the many common disorders associated with ED. Sexual histroy, physical examination, laboratory testing and somespecialised diagnostic tests (e.g. duplex ultrasound of the penis, nocturnal penile tumescence and rigidity test, intracavernous injection test and psychiatric assessment) can be used to diagnosis.

\section{Treatment of ED}

As a consequence of its multifactorial etiology, the treatment of ED in diabetic men requires a global approach. The first step is to correct the modifiable risk factors and to promote lifestyle changes, whereas the use of Phosphodiesterase 5 (PDE5) inhibitors represents first-line pharmacologic therapy, second-line therapy is other options (eg. Hormonal therapy/Vacuum therapy/LIST/İntracavernosal therapy)and finally the last step is surgical treatment.

\section{Glycemic Control and Lifestyle Modifications}

Tight glycemic control, so as to maintain an $\mathrm{HbA}_{1 \mathrm{c}}$ concentration $<7 \%$, is recommended for adults with diabetes to minimize the risk of long-term microvascular complications [37]. Although several studies demonstrate an association between poor glycemic control and the risk of ED, it is still not clear whether intensive glycemic control may have beneficial effects on erectile function. Many cross-sectional studies have shown that better glycemic control is associated with improved erectile function $[38,39]$.

Lifestyle changes, such as increased physical activity, a Mediterranean diet, and reduced caloric intake, have been associated with the amelioration of erectile function in the general male population. The suggested mechanisms by which weight loss, healthy diet, and physical exercise can improve erectile function include the amelioration of endothelial dysfunction, insulin-resistance, and low-grade inflammatory state associated with diabetes and metabolic diseases-all of which are risk factors for ED [40].

\section{Pharmacological Therapy and Other Therapies}

Oral PDE5-Is are now regarded as the first-line treatment for erectile dysfunction [41,42]. These drugs facilitate erection by inhibiting the PDE5 enzyme, which is specifically responsible for the degradation of cyclic Guanosine Monophosphate (cGMP) in the cavernous smooth muscles. This inhibition leads to the prolonged activity of cGMP which, in turn, reduces intracellular calcium concentrations, maintains smooth muscle relaxation, and results in rigid penile erections. Sildenafil, vardenafil, and tadalafil are commercially available worldwide. These drugs differ in their time to onset and in their duration of action, but they show the same efficacy and safety profile. All of them have shown their efficacy in diabetic 
patients [43], although it has been reported that diabetic men with $\mathrm{ED}$ are less responsive to PDE5 inhibitors when compared with nondiabetic men with ED [44]. Moreover, findings from both experimental and clinical studies reported that chronic or daily use of PDE5 inhibitors for ED may significantly improve endothelial dysfunction $[45,46]$. Mirodenafil is a new option for the treatment of erectile dysfunction in diabetes mellitus patients with sexual dysfunciton. İt is at least as effective as other PDE5 inhibitors [47]. In addition to treatment, udenafil and mirodenafil may be another option in daily dosing treatment for $\mathrm{ED}[47,48]$. CHD is not an absolute contraindication for PDE5 inhibitors therapy, but particular caution has to be paid in cases of unstable and severe angina pectoris, recent myocardial infarction, certain arrhythmias, poorly controlled hypertension, and concomitant use of nitrates or nitrate donors: before starting therapy with PDE5 inhibitors, diabetic patients should undergo an overall cardiovascular examination [49].

Testosterone Replacement Therapy (TRT) is recommended in men with ED who show low levels of testosterone [50]. Different formulations are available, such as gels, patches, tablets, implants, and injections. In a prospective, randomized, double-blind, placebo-controlled study, transdermal testosterone replacement therapy was associated with beneficial effects on sexual function in men with type 2 diabetes [51]. In the therapy of ED, particularly in patients with late-onset hypogonadism, TRT should be used in cases that are unresponsive to PDE-5 inhibitors, which promotes significant symptomatic relief. [52].

Vacuum Erection Devices (VEDs) provide passive engorgement of the corpora cavernosa, together with a constrictor ring placed at the base of the penis to retain blood within the corpora. Thus, erections with these devices are not normal because they do not use physiological erection pathways. Efficacy, in terms of erections satisfactory for intercourse, is as high as $90 \%$, regardless of the cause of ED and satisfaction rates range between $27 \%$ and $94 \%$ [53].

Penile extracorporeal Low-İntensity Shock Wave Therapy (LIST) to the penis has recently emerged as a novel and promising modality in the treatment of erectile dysfunction. LIST has angiogenic properties and stimulates neovascularization. If applied to the corpora cavernosa, LIST can improve penile blood flow and endothelial function. LIST has been shown to have a substantial effect on penile hemodynamics and erectile function in patients with vasculogenic ED. LIST is effective in patients who are responsive to Phosphodiesterase 5 İnhibitors (PDE5i) and can also convert PDE5i nonresponders to responders [54].

Intracavernosal injection of papaverine, phentolamine, and Prostaglandin E1 (PGE1) (alone or in combination), as well as the intraurethral administration of PGE1, are good alternatives for patients who do not respond to PDE5 inhibitors. Both of these two treatment modalities have demonstrated efficacy in ameliorating erectile function in diabetic patients [55,56].

\section{Surgical Therapy}

Penile prosthesis implantation, the third-line treatment for erectile dysfunction, is one of the few successful surgical treatments for erectile dysfunction. Implantation of a penile prosthesis is usually the last resort for treatment of erectile dysfunction, when other modalities have failed or are not preferred by the patient. There are two main types of penile prostheses. The semi-rigid prosthesis is usually easy to implant and lasts longer than the inflatable one. The hydraulic three-piece implant is the most popular penile prosthesis in the USA.

Other surgical treatments for erectile dysfunction include arterial bypass procedures, which are specifically indicated for traumatic injuries of penile arteries (and can potentially lead to cure of the erectile dysfunction), and venous ligation surgery for young men with congenital abnormal venous leakage; however, vascular surgery is rarely done nowadays.

\section{Acknowledgments}

The authors thank for your technical help and writing assistance.

\section{Disclosure}

The authors report no conflicts of interest in this work

\section{References}

1. (2014) International Diabetes Federation. IDF Diabetes Atlas. (6th edn). Brussels, Belgium: International Diabetes Federation.

2. Go AS, Mozaffarian D, Roger VL, Benjamin EJ, Berry JD, et al. (2013) Heart disease and stroke statistics-2013 update: a report from the American Heart Association. Circulation 127: 6-245.

3. Kopelman PG (2000) Obesity as a medical problem. Nature 404: 635-643.

4. Campos C (2012) Chronic hyperglycemia and glucose toxicity: pathology and clinical sequelae. Postgrad Med 124: 90-97.

5. Rahman S, Rahman T, Ismail AA, Rashid AR (2007) Diabetes-associated macrovasculopathy: pathophysiology and pathogenesis. Diabetes Obes Metab 9: 767-780.

6. Feldman HA, Goldstein I, Hatzichristou DG, Krane RJ, McKinlay JB (1994) Impotence and its medical and psychosocial correlates: results of the Massachusetts Male Aging Study. J Urol 151: 54-61.

7. Lu CC, Jiann BP, Sun CC, Lam HC, Chu CH, et al. (2009) Association of glycemic control with risk of erectile dysfunction in men with Type 2 diabetes. J Sex Med 6: 1719-1728.

8. Giugliano F, Maiorino M, Bellastella G, Gicchino M, Giugliano D, et al. (2010) Determinants of erectile dysfunction in Type 2 diabetes. Int J Impot Res 22: 204-209.

9. Seftel AD, Sun P, Swindle R (2004) The prevalence of hypertension, hyperlipidemia, diabetes mellitus and depression in men with erectile dysfunction. $J$ Urol 171: 2341-2345.

10. Esposito K, Ciotola M, Marfella R, Di Tommaso D, Cobellis L, et al. (2005) Sexual dysfunction in women with the metabolic syndrome. Diabetes Care 28: 756 .

11. (1993) NIH Consensus Conference Impotence. NIH Consensus Development Panel on Impotence. JAMA 270: 83-90.

12. Laumann EO, Paik A, Rosen RC (1999) Sexual dysfunction in the United States: prevalence and predictors. JAMA 281: 537-544.

13. De Berardis G, Franciosi M, Belfiglio M, Di Nardo B, Greenfield S, et al. (2002) Erectile dysfunction and quality of life in type 2 diabetic patients: a serious problem too often overlooked. Diabetes Care 25: 284-291.

14. Lewis RW, Fugl-Meyer KS, Corona G, Hayes RD, Laumann EO, et al. (2010) Orıgınal Artıcles: Definitions/epidemiology/risk factors for sexual dysfunction. J Sex Med 7: 1598-1607.

15. Johannes CB, Araujo AB, Feldman HA, Derby CA, Kleinman KP, et al. (2000) Incidence of erectile dysfunction in men 40 to 69 years old: longitudinal results from the Massachusetts male aging study. J Urol 163: 460-463.

16. Bacon CG, Mittleman MA, Kawachi I, Giovannucci E, Glasser DB, et al. (2003) Sexual function in men older than 50 years of age: results from the health professionals follow-up study. Ann Intern Med 139: 161-168. 
Citation: Ediz C, Altintas R (2014) Diabetes Mellitus and Sexual Dysfunction; A Systematic Review of the Literature with Current Treatment Approaches. J Diabetes Metab Disord 1: 001.

17. Ayta IA, McKinlay JB, Krane RJ (1999) The likely worldwide increase in erectile dysfunction between 1995 and 2025 and some possible policy consequences. BJU Int 84: 50-56.

18. Ponholzer A, Temml C, Mock K, Marszalek M, Obermayr R, et al. (2005) Prevalence and risk factors for erectile dysfunction in 2869 men using a validated questionnaire. Eur Urol 47: 80-85.

19. Bortolotti A, Fedele D, Chatenoud L, Colli E, Coscelli C, et al. (2001) Cigarette smoking: a risk factor for erectile dysfunction in diabetics. Eur Urol 40 392-396.

20. Giuliano FA, Leriche A, Jaudinot EO, De Gendre AS (2004) Prevalence of erectile dysfunction among 7689 patients with diabetes or hypertension, or both. Urology 64: 1196-1201.

21. Nicolosi A, Moreira ED, Shirai M, Bin Mohd Tambi MI, Glasser DB (2003) Epidemiology of erectile dysfunction in four countries: cross-national study of the prevalence and correlates of erectile dysfunction. Urology 61: 201-206

22. De Berardis G, Pellegrini F, Franciosi M, Belfiglio M, Di Nardo B, et al. (2007) Clinical and psychological predictors of incidence of self-reported erectile dysfunction in patients with Type 2 diabetes. J Urol 177: 252-257.

23. Esposito K, Giugliano F, Martedì E, Feola G, Marfella R, et al. (2005) High proportions of erectile dysfunction in men with the metabolic syndrome. Diabetes Care 28: 1201-1203.

24. Demir O, Akgul K, Akar Z, Cakmak O, Ozdemir I, et al. (2009) Association between severity of lower urinary tract symptoms, erectile dysfunction and metabolic syndrome. Aging Male 12: 29-34.

25. Rosen RC, Cappelleri JC, Smith MD, Lipsky J, Peña BM (1999) Development and evaluation of an abridged, 5-item version of the International Index of Erectile Function (IIEF-5) as a diagnostic tool for erectile dysfunction. Int J Impot Res 11: 319-326.

26. Thorve VS, Kshirsagar AD, Vyawahare NS, Joshi VS, Ingale KG, et al. (2011) Diabetes-induced erectile dysfunction: epidemiology, pathophysiology and management. J Diabetes Complications 25: 129-136.

27. Penson DF, Latini DM, Lubeck DP, Wallace KL, Henning JM, et al. (2003) Do impotent men with diabetes have more severe erectile dysfunction and worse quality of life than the general population of impotent patients? Results from the Exploratory Comprehensive Evaluation of Erectile Dysfunction (ExCEED) database. Diabetes Care 26: 1093-1099.

28. Goldstein I, Lue TF, Padma-Nathan H, Rosen RC, Steers WD, et al. (1998) Oral sildenafil in the treatment of erectile dysfunction. Sildenafil Study Group. N Engl J Med 338: 1397-1404.

29. Corona G, Giorda CB, Cucinotta D, Guida P, Nada E (2013) The SUBITO-DE study: sexual dysfunction in newly diagnosed type 2 diabetes male patients. $J$ Endocrinol Invest 36: 864-868.

30. Fedele D, Coscelli C, Santeusanio F, Bortolotti A, Chatenoud L, et al. (1998) Erectile dysfunction in diabetic subjects in Italy. Gruppo Italiano Studio Deficit Erettile nei Diabetici. Diabetes Care 21: 1973-1977.

31. Rosen RC (1997) Sexual dysfunction as an obstacle to compliance with antihypertensive therapy. Blood Press Suppl 1: 47-51.

32. Foresta C, Caretta N, Corona G, Fabbri A, Francavilla S, et al. (2009) Clinical and metabolic evaluation of subjects with erectile dysfunction: a review with a proposal flowchart. Int J Androl 32: 198-211.

33. Guay AT (2007) ED2: erectile dysfunction=endothelial dysfunction. Endocrinol Metab Clin North Am 36: 453-463.

34. Malavige LS, Levy JC (2009) Erectile dysfunction in diabetes mellitus. J Sex Med 6: 1232-1247.

35. Nehra A, Moreland RB (2001) Neurologic erectile dysfunction. Urol Clin North Am 28: 289-308.

36. Sáenz de Tejada I, Angulo J, Cellek S, González-Cadavid N, Heaton J, et al (2005) Pathophysiology of erectile dysfunction. J Sex Med 2: 26-39.
37. Skyler JS, Bergenstal R, Bonow RO, Buse J, Deedwania P, et al. (2009) Intensive glycemic control and the prevention of cardiovascular events: implications of the ACCORD, ADVANCE, and VA diabetes trials: a position statement of the American Diabetes Association and a scientific statement of the American College of Cardiology Foundation and the American Heart Association. Diabetes Care 32: 187-192.

38. Roth A, Kalter-Lftbovhx O, Kerbis Y, Tekenbaum-Koren E, Chen J, et al (2003) Prevalence and risk factors for erectile dysfunction in men with diabetes, hypertension, or both diseases: a community survey among 1,412 Israeli men. Clin Cardiol 26: 25-30.

39. Romeo JH, Seftel AD, Madhun ZT, Aron DC (2000) Sexual function in men with diabetes type 2: association with glycemic control. J Urol 163: 788-791.

40. Esposito K, Giugliano D (2011) Lifestyle/dietary recommendations for erectile dysfunction and female sexual dysfunction. Urol Clin North Am 38: 293-301.

41. Konstantinos G, Petros P (2009) Phosphodiesterase-5 inhibitors: future perspectives. Curr Pharm Des 15: 3540-3551.

42. Brant WO, Bella AJ, Lue TF (2007) Treatment options for erectile dysfunction. Endocrinol Metab Clin North Am 36: 465-479.

43. Vardi M, Nini A (2007) Phosphodiesterase inhibitors for erectile dysfunction in patients with diabetes mellitus.Cochrane Database Syst Rev CD002187.

44. Francis SH, Corbin JD (2011) PDE5 inhibitors: targeting erectile dysfunction in diabetics. Curr Opin Pharmacol 11: 683-688.

45. Ferrini MG, Kovanecz I, Sanchez S, Vernet D, Davila HH, et al. (2007) Long term continuous treatment with sildenafil ameliorates aging-related erectile dysfunction and the underlying corporal fibrosis in the rat. Biol Reprod 76 : 915-923.

46. Porsta H, Giulianob F, Glinac S, Ralphd D, Casabé AR, et al. (2006) Evaluation of the efficacy and safety of once-a-day dosing of tadalafil $5 \mathrm{mg}$ and 10 $\mathrm{mg}$ in the treatment of erectile dysfunction: results of a multicenter, randomized, double-blind, placebo-controlled trial. Eur Urol 50: 351-359.

47. Park HJ, Moon KH, Lee SW, Lee WK, Kam SC, et al. (2014) Mirodenafil for the Treatment of Erectile Dysfunction: A Systematic Review of the Literature. World J Mens Health 32: 18-27.

48. Cho MC, Paick JS (2014) Udenafil for the treatment of erectile dysfunction. Ther Clin Risk Manag 10: 341-354

49. Nehra A, Jackson G, Miner M, Billups KL, Burnett AL, et al. (2012) The Princeton III Consensus recommendations for the management of erectile dysfunction and cardiovascular disease. Mayo Clin Proc 87: 766-778.

50. Wang C, Nieschlag E, Swerdloff R, Behre HM, Hellstrom WJ, et al. (2008) Investigation, treatment and monitoring of late-onset hypogonadism in males: ISA, ISSAM, EAU, EAA and ASA recommendations. Eur J Endocrinol 159 507-514.

51. Jones TH, Arver S, Behre HM, Buvat J, Meuleman E, et al. (2011) TIMES2 Investigators Testosterone replacement in hypogonadal men with type $2 \mathrm{di}$ abetes and/or metabolic syndrome (the TIMES2 study) Diabetes Care 34 828-837.

52. Celik O, Yücel S (2013) Testosterone Replacement Therapy: Should It Be Performed in Erectile Dysfunction? Nephrourol Mon 5: 858-861.

53. Levine LA, Dimitriou RJ (2001) Vacuum constriction and external erection devices in erectile dysfunction. Urol Clin North Am 28: 335-341.

54. Abu-Ghanem Y, Kitrey ND, Gruenwald I, Appel B, Vardi Y, et al. (2014) Penile Low-Intensity Shock Wave Therapy: A Promising Novel Modality for Erectile Dysfunction. Korean J Urol 55: 295-299.

55. Williams G, Abbou CC, Amar ET, Desvaux P, Flam TA, et al. (1998) Efficacy and safety of transurethral alprostadil therapy in men with erectile dysfunction. MUSE Study Group. Br J Urol 81: 889-894.

56. Padma-Nathan H, Hellstrom WJG, Kaiser FE, Labasky RF, Lue TF, et al (1997) Treatment of men with erectile dysfunction with transurethral alprostadil. N Engl J Med 336: 1-7. 